\title{
Torture in Poland
}

Jerzy Umiastowski Gdansk, Poland

Torture was used in Poland from 1939-1989. Since then it has ceased.

During World War II torture in Poland reached a scale never known before in history. Six million Polish people were killed. Half of them were Polish Jews - or more correctly Jewish Poles. Their first language was Polish. They introduced tremendous values to Polish culture, science, art, and even folklore. The Holocaust was not only a Jewish tragedy, it was also a Polish tragedy.

World War II was over in Western Europe in 1945, but only ended in 1989 in Poland. Until that time torture was systematically used by the security forces. We are still finding the graves of victims tortured and killed by KGB agents and their Polish collaborators.

During the years 1945-1956 some forensic scientists, prison doctors and military doctors violated medical ethics by producing false death certificates, and sometimes by participating in torture. This problem needs careful examination.

The intensity of political repression and torture diminished after 1956 but increased again in 1968, and particularly in 1970 when, according to an official statement, 49 people were killed and 1200 injured during the anti-Communist revolt. At that time some doctors also produced false death certificates, and other false medical statements.

Both repression and torture greatly increased after the declaration of martial law on December 13, 1981. At that time Polish doctors behaved perfectly, often protecting people against repressive measures.

Some doctors produced false medical certificates in order to protect people - I do not think that was any violation of medical ethics. Unfortunately a few doctors collaborated with the security forces. Prison doctors accepted political prisoners for special penalties, for example hunger, exposure to cold, darkness and other forms of torture. They provided medical certificates which asserted that the prisoner was healthy and fit enough to undergo the penalty; there was no indication on these certificates that the doctors were against these sorts of penalty. Many people lost their lives in unclear circumstances: their death certificates need investigation and verification.

Today torturers as defined in the Declaration of Tokyo are not employed anywhere in Poland.

There used to be another type of violation of human: rights, one which hardly affected the population in general. This is the so-called 'nomenclatura' system. Under this system a list is held of names of people 'suitable' for high-ranking posts because of their political loyalty. This system is responsible for the susceptibility of our health service to ideological influences, for false statistical reports, for poor selection of people, for the censorship of medical information, and for many other abnormalities.

Now Poland is again a democratic country. The introduction of international principles of medical ethics is an urgent necessity for my country, and for Europe.

Ferzy Umiastowski, MD, is Senior Assistant in the Miejsky-Zaspa Hospital, Gdansk, Poland. 